\title{
PSYCHE
}

VOL. XLII

MARCH 1935

No. 1

\section{PRELIMINARY NOTE ON THE STRUCTURE OF THE PRETARSUS AND ITS POSSIBLE PHYLOGENETIC SIGNIFICANCE}

\author{
By Richard T. Holway \\ Biological Laboratories, Harvard University
}

The uncertain reliability of morphological structures for determining ancestral relations is well known and the extreme care and attention to the vagaries of parallelism, specialization, etc. so necessary for the development of valid theories have been rightly emphasized of recent years. However, in spite of its late disrepute, there is yet much to be learned from comparative morphology if sufficiently long series are studied and checked with the trends of parallel structures and if a most judicious interpretation of the evidence is demanded.

The primary purpose of this paper is to indicate the type of claw-segment found in the important insectan orders together with the common basic plan occurring throughout and also to outline possible homologies which further study and examination of selected and thoroughly representative series from each order may support. Although it is impossible at the present stage to offer any evidence substantial enough to warrant forming exact conclusions as to homologies from order to order, to say nothing of attempting to solve phylogenetic problems, there are without doubt most significant agreements in many cases which provide definite possibilities to be tested by further study. Especially important are those correlations which fall in with phylogenetic concepts already accepted (or debated) from the evidence of the comparative morphology of other structures. 
For example, the concurrence of Trichoptera and Lepidoptera is not questioned and some investigators have suggested that these two groups might even be conceived of as one valid order. The nature of the claw-segment of Astenophylax (Fig. 21) and Automeris (Fig. 22) shows at a glance the proximity of these structures even in such advanced representatives of the respective orders.

The relative value of a structure like the pretarsus as a phylogenetic guide may be uncertain, but the above example indicates that such consistency of the claw-segment from order to order should make it of considerable utility in checking theoretical relationships. Although the basic plan of the pretarsus presents a certain conformity throughout the orders, there are sclerites which are variable enough to warrant their investigation from the standpoint of taxonomy. For example, within the Hymenoptera the orbicula may be important in this respect. Hayes and Kearns (1934) have studied the empodium of Coleoptera and find that the Adephaga is the only group showing any consistancy in structure; they conclude, in general, that there is in some a tendency towards generic or family uniformity but that the super-families are decidedly heterogeneous. Arolia and pseudarolia have long been used as the basis of classification for the Miridae and for other Hemiptera the empodium may prove to be of taxonomic value.

\section{Acknowledgements}

The writer is indebted to Professor C. T. Brues and Professor G. C. Crampton for their advice during the preparation of this paper, and to them and to the Museum of Comparative Zoology for much of the material herein figured.

\section{Terminology.}

The general structure of the pretarsus has been figured many times for different orders: Snodgrass gives detailed descriptions of the condition in the honey-bee (1925) and figures several other types (1927) ; Crampton (1923) compares the claw-segment of Periplaneta with those of Leptid and Asilid Diptera; Hayes and Kearns (1934) have studied the pretarsus of Coleoptera and summarize past work on 
this structure; de Meijere's investigations are more extensive and cover all the important orders but his German terminology is not used at all in this country. A complete history of the terminology of the numerous parts of the claw-segment must be left for a later and more comprehensive study of this structure, therefore that system accepted by the more recent investigators is followed throughout. In some cases the same terms are used from order to order, even though true homology is not yet proved, instead of offering new names which in all probability would have to be discarded after further study supplied evidence to substantiate suspected homologies. However, all doubtful cases are indicated as such.

The following is a list of the terms herein used with their definitions and equivalents.

Apodeme (Unguitractor tendon, Sehne).-This is the tendon which runs from the unguitractor plate to the tibial musculature, the flexor of the claws. Supposedly the claws spring back into their normal position by natural resiliency when tension through the apodeme is released as there is no levator of the pretarsus in insects. (Crampton 1923) (Snodgrass 1929).

Arolium. In general the term arolium is restricted to a median paired or unpaired, pad-like structure which is articulated to the unguifer or arises from a position midway between the claws. Whether the complicated median structure of Hymenoptera, Lepidoptera and Trichoptera, the paired ribbon-like parts known as arolia in certain Hemiptera (Miridae), and the single median pad of Diptera and orthopteroid insects are all strictly homologous is problematical. However, the term arolium is here used to designate these structures in every order in which they occur, according to the definition above.

Basipulvilli. (auxilliæ). This term was first applied by Crampton (1923) to the small lateral sclerites at the bases of the pulvilli of Diptera and also to similar sclerites laterad of the unguitractor in Periplaneta although true pulvilli are not found in Orthopteroids. The auxilliæ (Hymenoptera), of MacGillivray, are evidently homologous with 
these structures but wherever such parts are found they are called basipulvilli in this paper.

Camera. (Bugel, or bow of Arnhart). Camera was originally applied to the curved narrow sclerite supporting the paired lobes of the arolium in Hymenoptera (MacGillivray). It is herein also used to designate the evident homologue in Trichoptera, Lepidoptera and Mecoptera.

Distitarsus. (onychium, digitus, ungula, etc.). The distal tarsal segment.

Empodium. (onychium). This term has been used for a variety of structures. Crampton (1923) finds that it should be restricted to a process of the unguitractor as found in Asilid Diptera and other orders. Hayes and Kearns (1934) accept this view and apply the term in their work on Coleoptera. Empodium is often used erroneously to refer to a pulvillus.

Flexor membranes. These are the membranous areas beneath the claws which apparently serve to transfer the tension of the apodeme on the unguitractor to the claws thus forcing them downwards. They are the areas from which, it has been suggested, the puvilli may have developed.

Gleitrinne or Gleitfläche (de Meijere). A prolongation of the ventral wall of the distitarsus. It is especially developed in Odonata and in some Coleoptera where it extends forward between the claws.

Onychium. This term has been used in such a variety of ways that it appears impossible to define it satisfactorily and therefore is not used in this paper.

Orbicula. In Hymenoptera, a small dorsal sclerite at the base of the arolium and distad of the unguifer. The orbicula is quite variable as to size and shape in this order and may be of taxonomic value.

Parempodia. (paronychia). Bristle-like appendages of the empodium. (Coleoptera and Hemiptera).

Planta. As used by Snodgrass, Crampton and MacGillivray planta applies only to the sole of the foot (typically in Hymenoptera and Orthoptera). However, the examples 
of most of the various orders observed show a plate which is probably homologous with the hymenopterous planta and therefore this term is used wherever practicable. Coleoptera, Diptera, Hemiptera, Dermaptera, Odonata and Ephemeroptera do not exhibit the planta in its typical condition although an empodium is present in these orders (except Ephemeroptera) which suggests the possibility that the empodium is merely a modified planta, closely associated with the unguitractor. Further study is needed to determine the correct relationships of these structures.

Snodgrass (1929) suggests that the planta may possibly be a subdivision of the unguitractor. However, the nature of the planta under high magnification is unlike that of the unguitractor which always gives a granulose appearance, is heavily sclerotized, and is sharply demarked in every case observed even to the primitive Odonata and Ephemeroptera. On the other hand the planta is variable in extent and degree of sclerotization and never shows the heavy, rugose aspect of the unguitractor. It seems more likely that the planta represents merely an area of the membranes distad of the unguitractor which has become sclerotized in greater or less degree according to the stress to which it is subjected by the tension of the apodeme and unguitractor. Of course the unguitractor itself is a sclerotized area of the membrane but it is always distinct in outline and not an indefinite structure as the planta often appears to be. (Note.-Planta has also been used to refer to the basal joint of the post tarsus in pollen-gathering Hymenoptera, to the soles of the post tarsal joints and to the anal clasping legs of caterpillars).

Pseudarolia.-Paired structure which occurs beneath the claws of some Hemiptera (Miridae) and which possibly will prove to bear some relation to pulvilli.

Pulvillus.-Originally referred to the pad-like structure beneath each claw in many Diptera. Other orders in which undoubted homologous parts occur are Lepidoptera and Trichoptera. Membranous areas are found beneath the claws in most orders but it is impossible to consider them as homologous with the pulvilli. In this paper they are 
termed flexor membranes. Crampton (1923) suggests two possible derivations for the pulvilli: either they arose as portions of a divided arolium (see condition in Hymenoptera, Fig. 26, Plecoptera, Fig. 7, and Mantispa, Fig. 19.) or they are detached membranous areas from the under side of the claws (see condition in some Ephemeroptera, Fig. 2, Homoptera and Hemiptera, Figs. 14 and 15, and the relation of basipulvilli to such membranous areas in Blattids.)

Ungues.-The claws.

Unguifer.-(tubercula, and Gelenkhöcker of de Meijere) refers to a small dorsal sclerite by which the claws are articulated with the distitarsus.

Unguitractor-(tarsulus, calcanea). This sclerite is the most constant structure of the pretarsus and is easily identified in all insects thus far observed because its general appearance is always the same though varying in size and shape. The surface of the unguitractor is sculptured to a greater or less degree with nodules which are sometimes almost spinelike. These nodules appear to correspond with the polygonal cells of the hypodermis and these cells may be seen through the chitin with high magnification. Snodgrass (1927) shows that in Tibicen this plate may be divided into two sclerites and also he figures in the membrane distal to the unguitractor, two small plates which he says may represent the arolium. It seems more likely that they are a divided planta but there is little evidence as yet for either supposition.

\section{Discussion. \\ ORDER ODONATA \\ Anax junius Drury. (Fig. 1)}

The claw-segment of Anax is simple and consists of the unguitractor plate (ut) with the expanded distal portion which is probably an empodium (em?) and of the lateral fleshy pads, flexor membranes (fm.), - which transmit tension to the ventral surfaces of the claws. The Gleitfläche of de Meijere, or thickened ventral portion of the 
distitarsus over which the unguitractor slides, is well developed in Odonata and a process of this structure extends beyond the bases of the ungues (un). The only other orders in which this condition has been observed are Coleoptera and Hemiptera.

ORDER EPHEMEROPTERA

Siphlonurus sp. (Fig. 2)

The unguitractor is a small pear-shaped plate and the claws (un) are simple. The important feature in this case is the membranous pad-like structure (pv?) closely applied to the ventral surface of each of the ungues. It is this condition which has led Crampton to suggest that possibly the pulvilli (Diptera) were derived from some such situation, that is, a splitting off of a ventral membrane from the claw itself. Proximally these pad-like structures are closely associated with the membranous areas transmitting tension from the unguitractor to the claws and in fact give evidence of being continuous with them.

Although these examples of Odonata and Ephemeroptera both show their elementary position, (absence of arolium, planta, basipulvilli or other significant structures), they give no evidence of any close relationship for the presence of an empodium in Anax indicates a certain amount of specialization. Thus, if these cases prove to be typical, the conclusions to be derived from the comparative morphology of the pretarsus will evidently be in agreement with the general conception of the relative positions of these orders.

\section{CURSORIAL ORTHOPTERA}

\section{Blattidae-Periplanta americana L. (Fig. 3)}

The arolium (ar) is large in this family, although its structure is simple compared with the complicated types found in the higher orders. Ventrally it is membraneous and concave, so that it forms a most efficient adhering organ. The unguitractor is typically large and heavily sclerotized. Two other structures of importance appear in this group. The planta $(\mathrm{pl})$ is a median quadrate plate just distal to the unguitractor and seems to be lightly sclerotized; it bears a single large seta. On either side of the planta is a 
small sclerite, the basipulvillus (bp) of Crampton, from which the retractile membrane leads to the under side of the claw. The relation of these membranes to the basipulvilli (where they are present) is the same throughout the orders and with further study should present interesting evidence with respect to the hypothesis that the pulvilli are evolved from such membranes.

Mantidae-Tenodera sinensis Saussure. (Fig. 4)

An arolium has not been found in Mantids thus far observed and such a structure is probably absent in this family. The general plan follows closely that of the roach although a seta is not present on the planta. The flexor membranes are large and especially noteworthy are their lateral expansions which if further produced might easily take on the appearance of pulvilli!

\section{ORDER ISOPTERA}

Termopsis angusticollis Walker (Fig. 5)

Again, in this case the basic plan follows closely that of the Blattid; however, the planta is much smaller than in either Mantid or Blattid and the seta does not arise from the planta itself but from the membrane. This condition might be taken as evidence for the view that the planta is a variable sclerotized area of the membrane between the claws. Although there is no arolium we find between the bases of the claws in winged termites a small plate (ar?) which undoubtedly represents an abortive arolium for in winged specimens of Mastotermes, a definite arolium, even though small and rudimentary, is present. Unguitractor and basipulvilli, as in the Mantid, show no significant variations from the Blattid type.

The proximity of these three groups has been noted many times by students of insect morphology so that such a correlation in type of pretarsus is not surprising. This combination appears even more natural when contrasted with the equally coherent union (from the standpoint of Pretarsus) of the Saltatorial Orthoptera. 


\section{ORDER EMBIOPTERA \\ Oligotoma sp. (Fig 6)}

In this order we again find the Blattid type; the planta is more extended laterally and is in contact with the basipulvilli on either side. There is no arolium and the flexor membranes are large and slightly expanded. There seems to be nothing particularly outstanding about the claw-segment of this insect but in general it approaches that of the Plecopteran to such a degree as would not prohibit the conception that these two orders are related.

\section{ORDER Plecoptera \\ Pteronarcys dorsata Say (Fig. 7)}

Pteronarcys shows the lateral basipulvilli and median planta as found in cursorial Orthoptera and termites. The arolium is a large and complicated structure which is made up of three lobes: a median portion or true arolium, and two lateral smaller pads beneath the claws which may be secondary divisions of the arolium or pulvilli which have become fused with the arolium. A more complete study of the Plecoptera may settle this question if intermediate forms can be found. On the other hand, it is possible that this structure represents a new development with no traceable homologies to the parts referred to above. (This also applies to similar lobes beneath the claws of many Homoptera and Hemiptera, to be discussed later). Dorsally, the membranous pads are supported by chitinous plates (indicated by broken lines) and the median lobe bears iwo clusters of small setæ on its ventral surface. The presence of planta and basipulvilli make it unlikely that the Plecoptera should be considered with the Archipterygota.

\section{SALTATORIAL ORTHOPTERA \\ Locustidae-Melanoplus bivittatus Say (Fig. 8)}

A large arolium has been found in all Locustids observed as contrasted to Tettigoniids and Gryllids in which this structure probably does not occur. It should be noted that the presence or absence of an arolium is not a condition which is constant for an order, but further study should 
produce information concerning its consistency in groups below ordinal rank. The absence of basipulvilli is characteristic of all the leaping Orthoptera and it is this factor which gives such a clear-cut division between the two orthopteroid groups. The planta of Melanoplus is more heavily sclerotized than the representatives of Tettigoniidae and Gryllidae which were examined.

Tettigoniidae-Ceuthophilus maculatus Say (Fig. 9)

Except for the absence of arolium and basipulvilli, the condition of the planta seems to be the only important feature of Ceuthophilus. This structure is not as heavily sclerotized as it is in Melanoplus and is quite different in shape. Often the planta is so lightly demarked, especially in small insects, that its boundaries are almost indistinguishable from the surrounding membrane.

Gryllidae-Gryllus pennsylvanicus Burm. (Fig. 10)

Gryllus gives us the first radical variation in the unguitractor for here the form is quite different from anything else found among the Orthoptera. This sclerite is characterized by a longitudinal V-shaped ridge or protuberance, the significance of which must remain in doubt until series are studied in groups below the order. It is possible that the less notable variations (chiefly in outline) of the unguitractor observed in these orthopteroid families will prove to be consistent to some degree. The planta may be easily compared with that of Ceuthophilus and differs mainly in the length of the lateral arms and the nature of the posterior margin.

Gryllotalpidae-Gryllotalpa borealis Burm. (Fig. 11)

Considerable modification of the planta is exhibited by Gryllotalpa and its condition in this insect is one of the factors suggesting a close relationship between planta and empodium. Note the numerous large setae and the manner in which the anterior portion of the unguitractor merges with the flexor membranes and planta. Comparison of the latter with the corresponding structure in Ceuthophilus and Gryllus indicates that it is a planta.

Empodium by definition refers to a process of the unguitractor, but this term must also apply to certain structures 
closely associated with the unguitractor which are not actual processes of it. Eg., the setiform empodium of Asilid Diptera is articulated with the unguitractor rather than continuous with it; also the coleopterous empodium in many cases gives some evidence that it may be retracted within (or beneath?) the unguitractor as pointed out by Hayes and Kearns. At any rate the empodium is not necessarily a distinct part of the unguitractor, so that the condition in Gryllotalpa may be intermediate between the typical isolated planta (as of Melanoplus) and the empodium of many Coleoptera where there is no discernable break between this structure and the unguitractor. Ceuthophilus and Gryllus may represent a step beyond the Melanoplus type towards closer association of planta with unguitractor.

About all that can be definitely said for the Saltatorial Orthoptera (sensu strictu) at the present time is that they are linked by a universal absence of basipulvilli and by the nature of other more variable features such as planta and flexor membranes. In any case there appears to be a wealth of material to be investigated within this group.

Phasmidae-Anisomorpha buprestoides (Stoll) (Fig. 12)

The absence of basipulvilli would place the Phasmids with Saltatorial rather than Cursorial Orthoptera and this is in agreement with conclusions presented by students of other structures. The unguitractor is narrower than in other Orthopteroids, while the planta is more heavily sclerotized and is triangular in outline, but is distinct from the unguitractor, a condition nearer to that of Locustids than to the other Saltatorial Orthoptera. The arolium is large and is reinforced dorsally by thickened ridges. On the whole the condition of the claw segment of this insect may be considered as supporting the general conception of the position of this family, $i$. e., related to the Saltatorial Orthoptera but developed along its own line of specialization.

\section{ORDER DERMAPTERA}

Psalis sp. (Fig. 13)

Apparently basipulvilli and planta are missing in Psalis. If this proves to be true for all Dermaptera, the order will 
be set off from the Blattid group on the one hand, and the remainder of the orthopteroid insects on the other. (Speaking from the standpoint of pretarsus only, of course). The unguitractor of Psalis is interesting because of its anterior projection (em?) which could be considered either empodium or planta; superficially, this structure appears to be continuous with the unguitractor and therefore more like a coleopterous empodium except that its margins are vague and it is not heavily sclerotized, $i$. e., more like a planta. It should be noted and may prove to be significant that all examples of Coleoptera thus far observed show neither basipulvilli nor planta but do have an empodium, whereas all specimens of most higher orders studied are fundamentally of the Blattid type with numerous secondary specializations.

\section{ORDER HOMOPTERA \\ Agallia constricta Van Duzee (Fig. 14)}

The small unguitractor bears a triangular empodium (em) which in turn is provided with a single heavy seta or parempodium (pem). As there seems to be considerable variation in the number of setae and in the shape of the empodium among the Homoptera, this group must be more fully studied to determine the extent and constancy of such variations. Attached to the under surface of the claws and extending beyond their tips are large membranous pads (pv?) which are reinforced meso-dorsally by small sclerotized areas. There are no basipulvilli.

The pretarsi of Cicadidae are not of this type nor do they show any features characteristic of the more advanced Hemiptera. As figured by Snodgrass (1927) the unguitractor of T. septendecim is divided into two plates; there is no empodium, but two small setae-bearing sclerites occur in the membrane between the claws, and Snodgrass suggests that these may represent the arolium but there seems to be more reason to consider them as a divided planta. In $T$. cinera these plates are very faint and difficult to distinguish from the surrounding membrane. There are no pads beneath the claws. 


\section{ORDER HEMIPTERA \\ Brochymena arborea (Say) (Fig. 15)}

The large triangular unguitractor is extended anteriorly to form a quadrate empodium which bears a parempodium on each of two lateral protuberances. Beneath the claws are pad-like structures ( $p v$ ?) reinforced by chitinous plates but not attached to the claws beyond their bases in contrast to the condition in Membracidae, Cicadellidae, etc. Although it seems very probable that these pads will prove to be identical with those of the Homoptera, but separated from the claws, it is more questionable whether they can be considered as homologous to the pulvilli of higher orders especially because of the fact that typical basipulvilli do not appear in the Hemiptera-Homoptera. The condition in these groups, however, possibly indicates a way in which sub-ungual pads may be developed and split off from the claws. Further reduction of the membranes might result in the typical pseudarolia of the Mirids! It is hoped that an extensive study of the Hemiptera-Homoptera will illuminate the relations of these various structures.

\section{ORDER COLEOPTERA}

Phyllophaga fusca Froe. (Fig. 16)

As mentioned above, the empodium, rather than basipulvilli and planta, is the characteristic feature of Coleoptera. In this specimen the unguitractor is narrow and the empodium is expanded distally into a broad plate which bears two parempodia or large setae. Each claw is provided with a large median tooth.

Hayes and Kearns have figured many specimens from this order and although they find the empodium absent in many cases, there seems to be a typical fundamental plan for the coleopterous pretarsus. That is: First, a well developed unguitractor with or without some form of empodium which in turn may or may not bear parempodia; Second, total absence of any membranous structures which could represent arolia, pulvilli, etc. Hayes and Kearns find that "some cleared specimens show what appears to be a basal part of the empodium withdrawn into the body of the 
unguitractor." This condition is evidently the same as that here shown in Phyllophaga fusca, (Fig. 16) in which the broken lines indicate the basal part referred to. It is questionable whether this is really within the unguitractor; this portion of the empodium might be beneath the unguitractor, or, merely a degree of sclerotization.

There is considerable similarity between the claw-segments of Dermaptera and Coleoptera. Although the empodium of Coleoptera is of course much more varied than that of Dermaptera, these orders agree in the absence of other significant structures. Some of the figures from Hayes and Kearns in which the empodium is absent are strongly reminiscent of the condition in Psalis, as in the latter, the area distad of the unguitractor is rather indefinite so that it is not difficult to imagine the sclerotization of this area to form the kind of empodium characteristic of Coleoptera-or its total lack of sclerotization with a resulting absence of empodium which is also a condition commonly found in Coleoptera. This must remain pure speculation, however, until checked by further study.

\section{ORDER NEUROPTERA \\ Sialidae-Corydalis cornuta L. (Fig. 17)}

There is no arolium but the planta is large and the basipulvilli are contiguous with its lateral margins. The claws are simple and the unguitractor is triangular like that of Ithone. In general the pretarsus of Corydalis is surprisingly different from that of Mantispa, but except for the absence of arolium and basipulvilli setae, it is easily comparable to the claw-segment of Ithone.

\section{Ithonidae-Ithone sp. (Fig. 18)}

The arolium is a median pad somewhat like that of $P$. americana, but much smaller and without the ventral concavity of the latter. The relations of planta and basipulvilli are of the Blattid type, but the planta is very lightly sclerotized and is continuous with the arolium, so that it might almost be considered as a part of this structure. The basipulvilli occupy the normal position and are provided with three setae, incidentally, the only case observed where 
the basipulvilli bear setae. The unguitractor and claws are not distinctive.

The similarity of the claw-segment of Ithone with that of the Blattids is evident and perhaps significant, for this insect is considered to be the most primitive of the Plannipennia. Comparison of Figs. 17, 18 and 19 illustrates why Ithone may be considered as annectant between Corydalis and Mantispa.

\section{Mantispidae-Mantispa brunnea Say (Fig. 19)}

The pretarsus of Mantispa is provided with a complicated type of arolium which has probably developed from a simple pad such as found in Ithone. Two fleshy lobes are supported by lightly sclerotized areas, indicated by broken lines, and at the base, posteriorly, are two cvoid sclerites also serving as supports. There is evidently no planta, a condition consistent with the light sclerotization of the planta in Ithone. At present it is impossible to interpret the significance of these various parts in Mantispa but it is hoped that other specimens of Neuroptera will make it possible to find homologies with the structures of higher insects. The basipulvilli are large and extend laterally a short distance along the membranes. The claws are broad and pectinate; the unguitractor differs considerably in outline from that of Corydalis or Ithone and bears a median ridge. It will be noted that the claw-segment of Mantispa is not comparable to that of Corydalis in any of its features and, in fact, the divergency of these two types is greater than any variations found in other orders, a condition which emphasizes the fact that the Neuroptera are known to be a highly diversified group.

\section{ORDER MECOPTERA}

Panorpa rufescens Rambur (Fig. 20)

The unguitractor is oval and bears a conspicuous median ridge such as is found in Mantispa; the claws are pectinate. A rod-like planta extends between the bases of the claws and the basipulvilli. The arolium is simple and is supported by a curved structure $(\mathrm{cm})$ which is probably the same as the camera of Hymenoptera. 


\section{ORDER TRICHOPTERA}

Astenophylax argus Harris (Fig. 21)

The arolium is much like that of Panorpa and differs only in the curvature of the camera which is U-shaped in Astenophylax. The planta is also similar, that is, a narrow rodlike structure distad of the unguitractor. The basipulvilli are large and are located at the bases of the leathery pulvilli (pv) which are heavily fringed with long narrow scales. The claws are simple instead of pectinate and the median ridge is absent from the unguitractor,-two features in contrast to the condition in Panorpa.

\section{ORDER LEPIDOPTERA Automeris io Fab. (Fig. 22)}

The claw-segment of Automeris is very similar to that of Astenophylax and varies only in the narrower, curved pulvilli and the nature of the arolium which gives evidence of developing a secondary lobe. The condition in many Lepidoptera where the arolium is lacking has not been investigated.

This agreement between Lepidoptera and Trichoptera was to be expected, although such a complete resemblance is perhaps surprising. There are also certain features traceable to Panorpa. (see Figs. 20 and 22). It is conceivable that some Mecopteran will be found with traces of pulvilli which appear to be common structures in the orders Lepidoptera, Trichoptera and Diptera. There can be no question but what the condition in Panorpa approaches that of the Trichoptera and Lepidoptera more closely than it does the Neuropteran types, except for the absence of pulvilli.

\section{ORDER DIPTERA}

Tabanidae-Tabanus atratus Fab. (Fig. 23)

The unguitractor is broadly triangular and the pulvilli and basipulvilli are typical. The arolium is articulated with the unguifer and on the ventral surface its membrane is continuous with that surrounding the basipulvilli and unguitractor. This is the structure erroneously referred to as pulvilliform empodium; it is really an arolium. (Cramp- 
ton 1923). The arolium of Tabanus is simple and lacks the supporting sclerite, or camera. For this reason there may be some question as to its strict homology with the arolium of Mecoptera, etc. described above. The absence of a planta may be significant as a similar absence was noted in Mantispid Neuroptera. On the other hand, the arolium is like that of Ithone in nature $i$. e., its ventral surface is continuous with the membrane distad of the unguitractor) and the planta of Ithone is so lightly sclerotized that it is conceivable that in many related forms the planta would be entirely absent.

Asilidae-Diogmites umbrinus Loew. (Fig. 24)

This insect has no arolium but is characterized by the presence of a setiform empodium, a long chitinous setiform structure arising from the distal margin of the unguitractor. The pulvilli are also long and narrow and similar to those of Trichoptera and Lepidoptera, but the basipulvilli are small.

A study of more primitive Diptera may bring out some annectant features which will be significant in regard to the origins of this order. Thus far there seems to be more common features in the Neuroptera than in the Mecoptera.

ORDER HYMENOPTERA

Siricidae-Tremex columba L. (Fig. 25)

The unguitractor is long and grooved and the basipulvilli are very small; pulvilli probably do not occur in the Hymenoptera. Tremex lacks an arolium which is a complicated structure when present in this order. The planta bears four setae and the claws are provided with a large median tooth or spur. The orbicula $(\mathrm{rb})$ is a dorsal sclerite which is here shown only in part.

\section{Sphecidae-Chalybion cæreuleum L. (Fig 26)}

The arolium, here shown extended, is normally folded back against the planta when not in use. Except for the paired lobes this structure is much like that of Panorpa especially in reference to the camera. The planta is provided with many small setae and the unguitractor differs 
from that of Tremex in outline and absence of dorsal grooves. The claws are simple and the basipulvilli small. The orbicula, a small dorsal sclerite, is not shown in this view but this plate is variable throughout the Hymenoptera and together with the planta and unguitractor should prove valuable in studying the inter-relations within the order. As with the Diptera, it seems probable that further study of primitive types will be of phylogenetic value for the variety of structures does provide a wealth of material to work on.

\section{Summary.}

Without losing sight of the fact that only a few specimens selected at random from each order are studied, the evidence thus secured does seem to point out certain tentative hypotheses to be further investigated.

1. That the planta occurs in most of the insectan orders as a sclerotized area of the membrane just distal to the unguitractor and that this structure is homologous throughout by position, ie., its relation to the unguitractor, basipulvilli and claws. The presence of one or more setae may be a distinguishing feature; note the condition in cursorial Orthoptera and Hymenoptera. The degree of sclerotization is quite variable for in some cases the planta is almost entirely membranous while in others it forms a heavy plate.

2. That the empodium is a highly modified planta. No planta was found (in specimens so far observed) in the orders Diptera, Hemiptera, Coleoptera and Dermaptera but an empodium is present in at least some representatives of all these orders. On the other hand, wherever a planta occurs an empodium has not yet been observed. The condition of the planta in Gryllotalpa and Psalis, where it is closely associated with the unguitractor, illustrates how difficult an attempt to distinguish between these two structures may be. Comparison of Gryllotalpa with other Orthopteroids leaves but little doubt but what the part referred to is a planta even though numerous setæ are present, for such appendages also occur on the plantæ of cursorial Orthoptera and Hymenoptera. The occurrence of parempodia, which are really setae, on the empodia of Coleop- 
tera and Hemiptera may also point to a close relation between these structures. These considerations, if supported by further investigation, indicate that the empodium is really a specialized planta, i. e., a planta which has become closely associated with the unguitractor and in some cases lengthened into a setiform process.

3. That the arolium or median pad-like structure occurring in many insects, although varying in complexity, is homologous throughout the orders. This structure is not of ordinal significance for it is present in some groups and absent from others within most orders.

4. That the small lateral sclerites (basipulvilli) are homologous in all orders; they form a support at the bases of the pulvilli when the latter are present and in such cases there is no question as to their homology. Many insects show these sclerites without the pulvilli but all other relationships are the same.

5. The problem of the origin of the pulvilli remains in doubt. Very possibly further study will support the suggestion of Crampton (1923) that they are membranous areas detached from beneath the claws. Thus far what evidence there is remains inconclusive, that is, briefly: the membranous claws of Ephemeroptera and the similar condition in certain Homoptera (Fig. 15) ; the pseudarolia of Miridæ which may be true pulvilli; the association of pulvilli and basipulvilli in Diptera, Trichoptera and Lepidoptera and the fact that the basipulvilli (if present) are always located at the bases of the flexor membranes in orders where typical pulvilli do not occur.

6. An interesting condition is that found in the orthopteroid insects. The similarity of certain anatomical features of the Blattidæ, Mantidæ and Isoptera is well known so that the agreement found in the claw-segments of these three groups is not surprising. The saltatorial Orthoptera, including the Phasmidæ, are also set apart as a coherent group by the nature of the pretarsus and the Dermaptera would seem to present a third Orthopteran type although less distinct and nearer to the Tettigoniids and Gryllidsplus coleopterous affinities. 
7. That the planta and basipulvilli found in the Plecoptera would place this order with the Neopterygota rather than with such types as Odonata and Ephemeroptera in which parts as advanced as the above have not been found although the presence of an empodium in Odonata must be considered.

8. At this stage it is impossible to attempt any valid correlations between the types of pretarsi found in the higher orders other than such obvious relations as that of Trichoptera to Lepidoptera. However, it is evident that the variations of the several parts of the pretarsus found among the Holometabola, even in such a random selection of cases, warrant a thorough investigation of the condition in these orders with a view to possible clarification of the phylogenetic implications concerned.

\section{Literature Cited}

Arnhart, L. (1923). Das Krallenglied der Honigbiene. Archiv f. Bienenkunde, 5:37-86, $1 \mathrm{pl}$.

Crampton, G. C. (1923). Preliminary note on the terminology applied to the parts of an insect's leg. Canadian Ent., $55: 126-132$.

Hayes \& Kearns. (1934). The pretarsus (articularis) in Coleoptera. Ann. Ent. Soc. American, 27 : 21-33, 41 figs.

MacGillivray, A. D. (1923). External insect-anatomy. Urbana, Ill.

deMeijere, J. C. H. (1901). Ueber das letzte Glied der Beine bei den Arthropoden. Zool. Jahrb., Anat. 14:417-476, pls. 30-37.

Snodgrass, R. E. (1925). Anatomy and physiology of the honey-bee. McGraw-Hill Co., New York.

(1927). Morphology and mechanism of the insect thorax. Smithsonian Misc. Coll., 80, No. 1, 108 pp., 44 figs.

(1929). The thoracic mechanism of a grasshopper and its antecedents. Smithsonian Misc. Coll., 82, No. 2, 111 pp., 54 figs. 
Psyche, 1935

Vol. 42, Platte I.

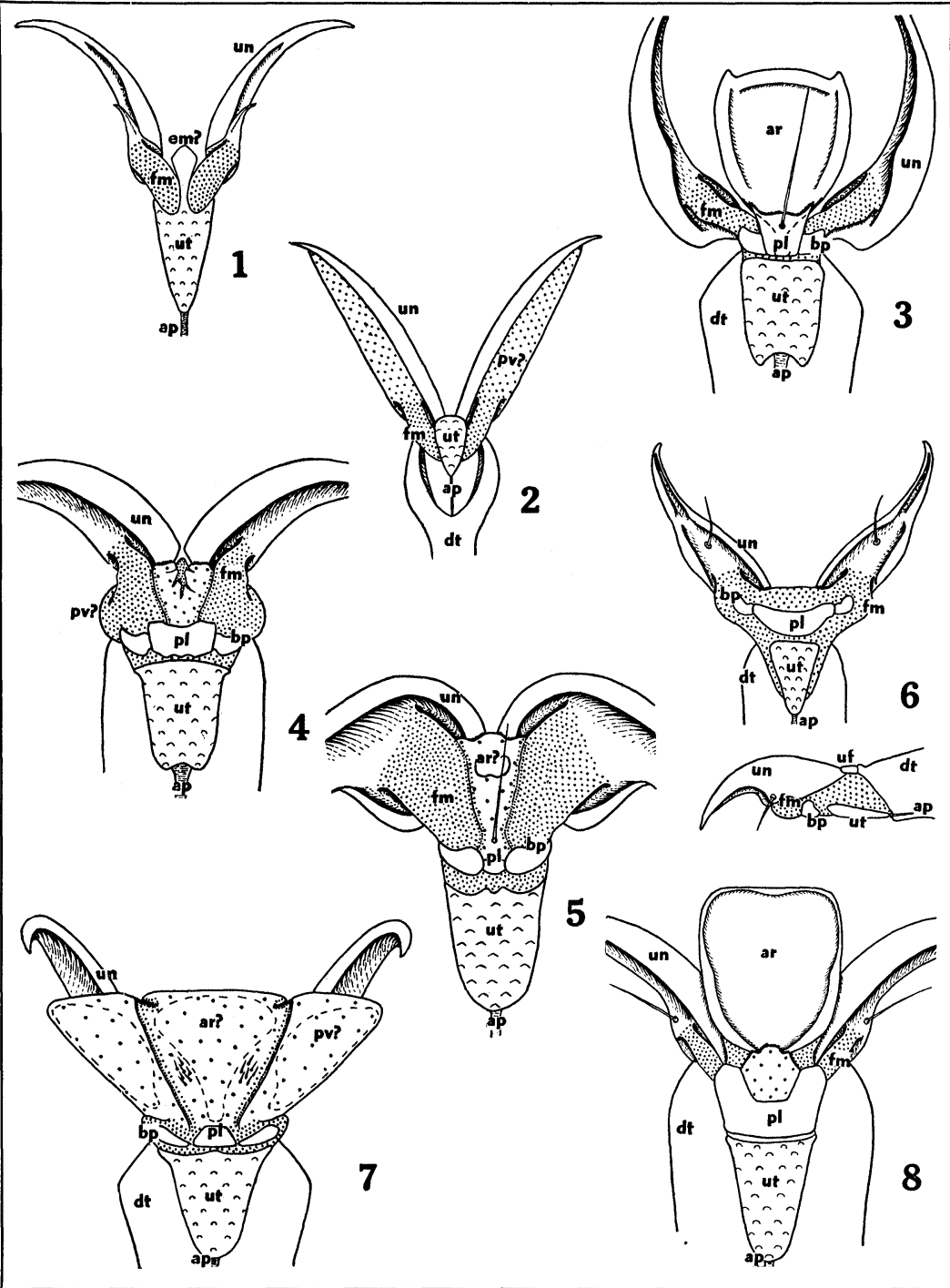

FIg. 1. Anax junius Drury.

FIG. 2. Siphlonurus sp.

FIG. 3. Periplaneta americana L.

Fig. 4. Tenodera sinensis Sauss.
FIG. 5. Termopsis angusticollis Walker.

Fig. 6. Oligotoma sp.

Fig. 7. Pteronarcys dorsata Say. Fig. 8. Melanoplus bivittatus Say. 
Vol. 42, Plate II.
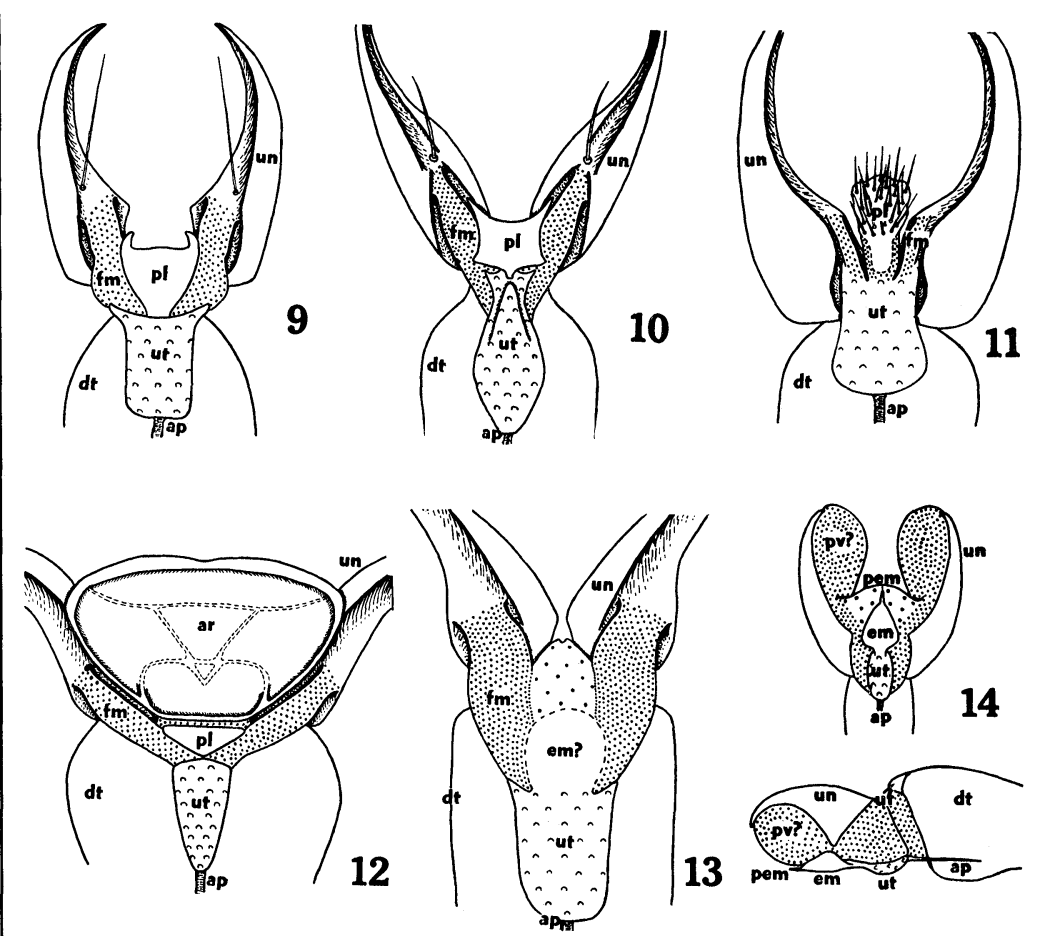

14

13
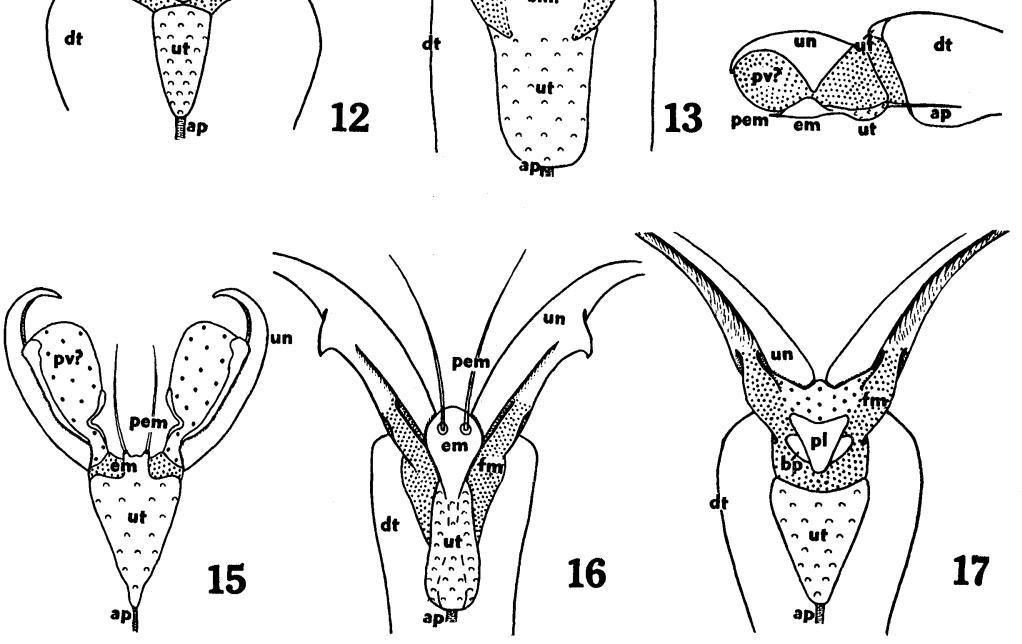

Fig. 9. Ceuthophilus maculatus Say.

FIG. 10. Gryllus pennsylvanicus Burm.

Fig. 11. Gryllotalpa borealis Burm.

FIG. 12. Anisomorpha buprestoides Stoll.

FIg. 13. Psalis sp.

FIG. 14. Agallia constricta Van Duzee, ventral and lateral views.

Fig. 15. Brochymena arborea Say.

Fig. 16. Phyllophaga fusca Froelich.

FIG. 17. Corydalis cornuta L. 
Psyche, 1935

Vol. 42, Plate III.
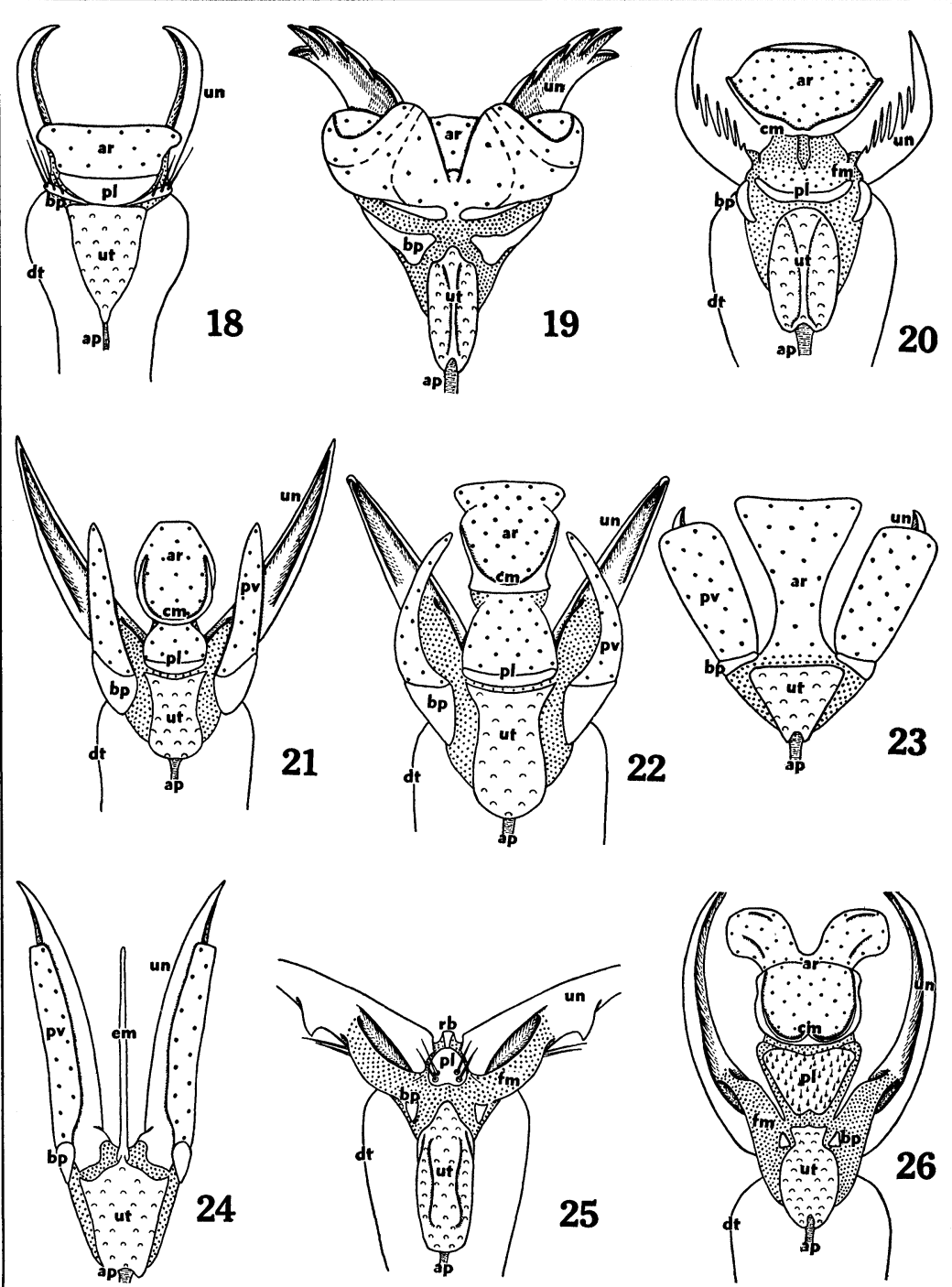

FIg. 18. Ithone sp.

Fig. 22. Automeris io Fabr.

Fig. 19. Mantispa brunnea Say. Fig. 23. Tabanus atratus Fabr.

FIg. 20. Panorpa rufescens Ram- FIG. 24. Diogmites umbrinus Loew. bur.

FIg. 25. Tremex columba L.

FIG. 21. Astenophylax argus FIg. 26. Chalybion caeruleum L. Harris. 


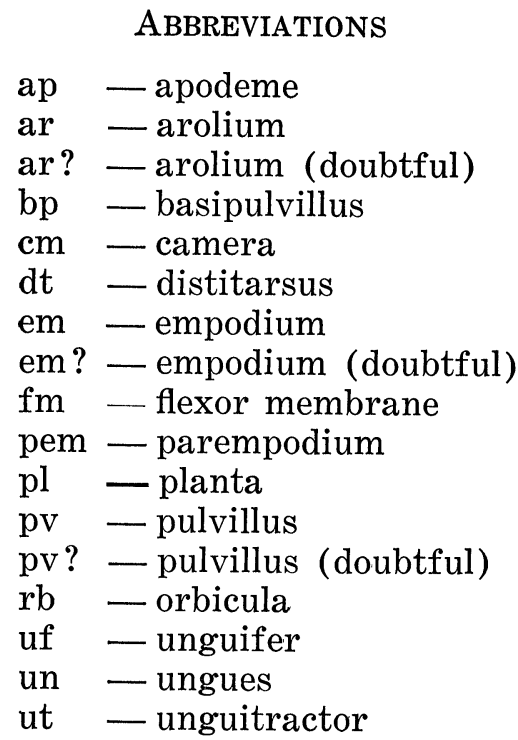

Except where otherwise noted the pretarsi figured were taken from the right meta-tarsus and are ventral views. 

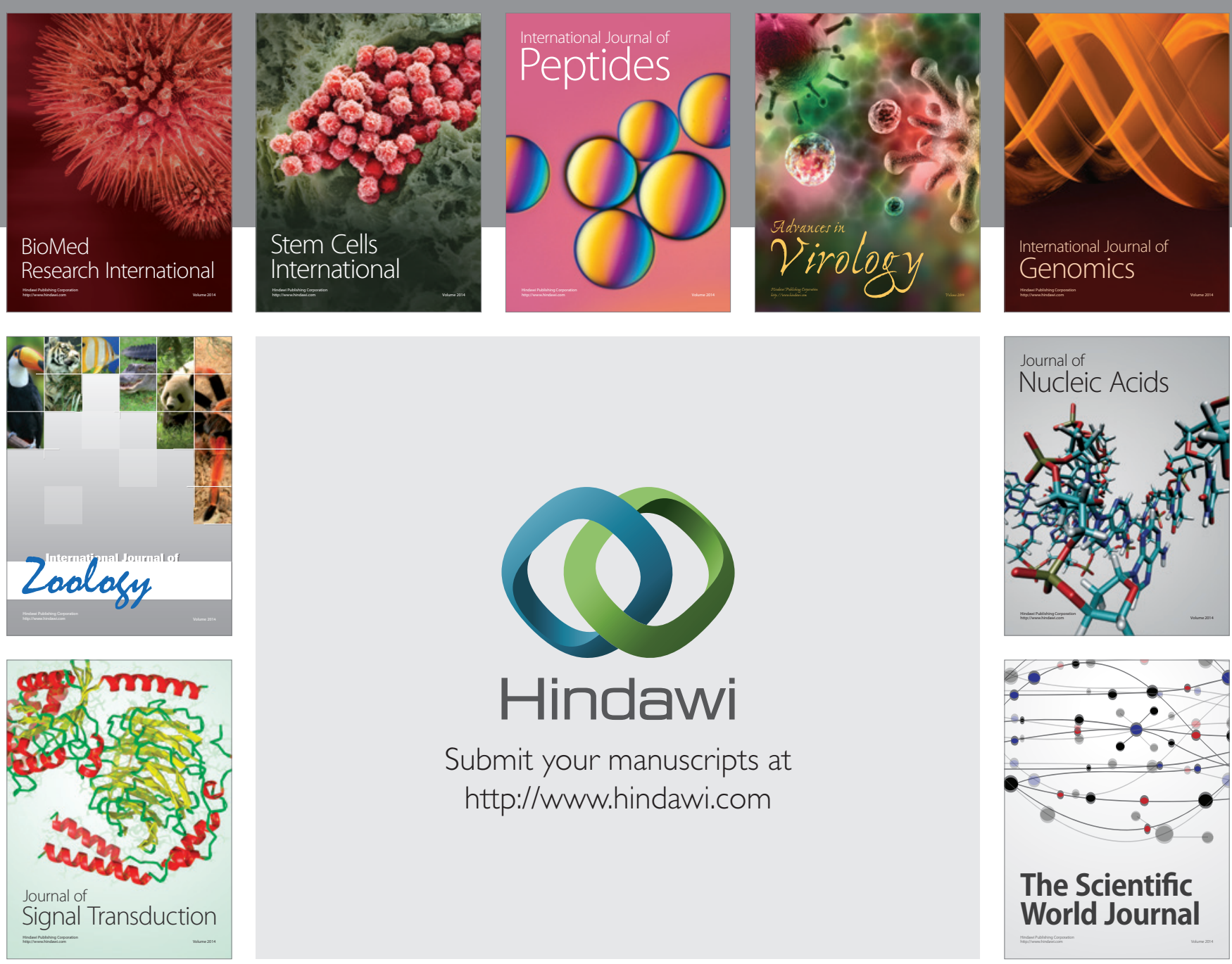

Submit your manuscripts at

http://www.hindawi.com
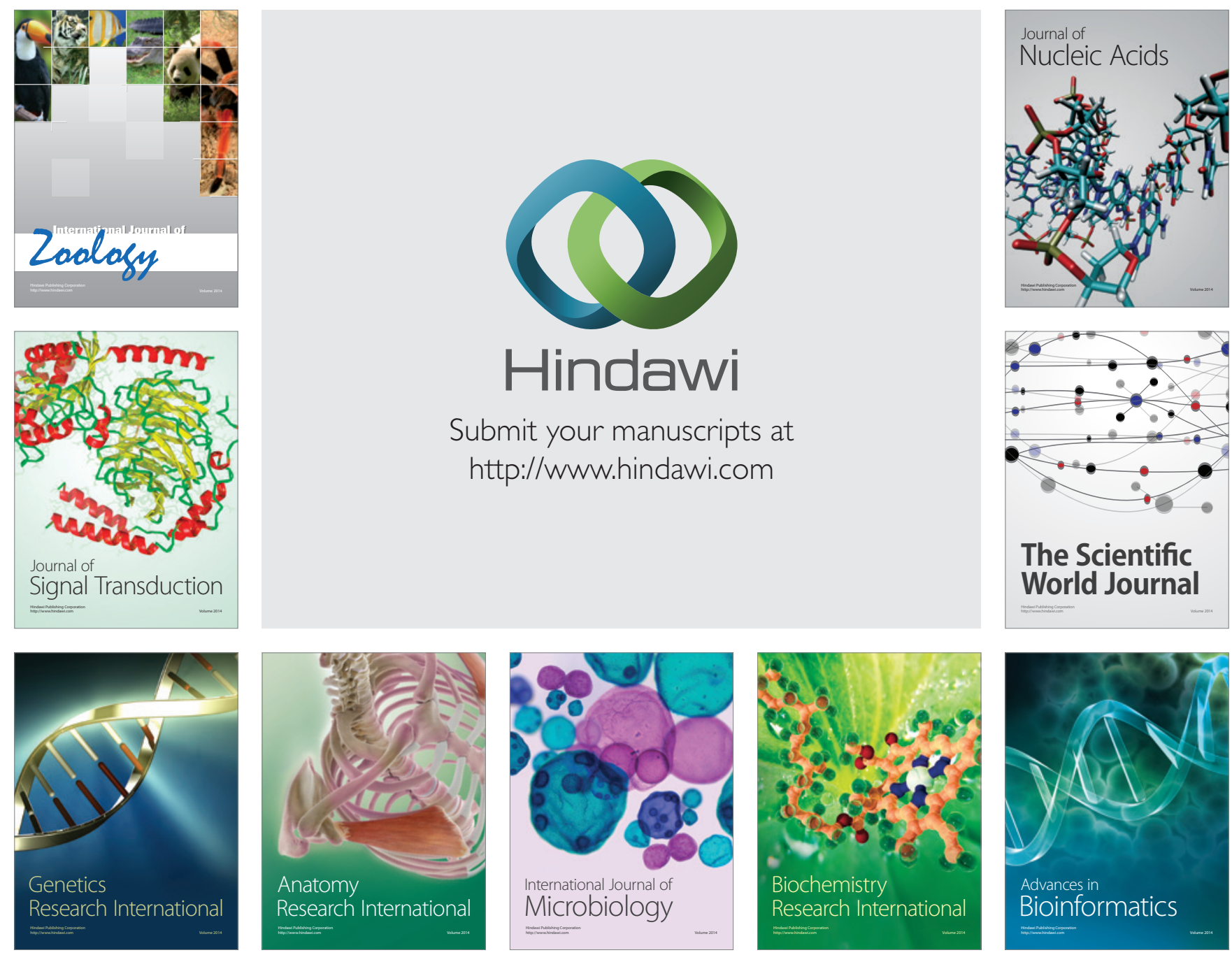

The Scientific World Journal
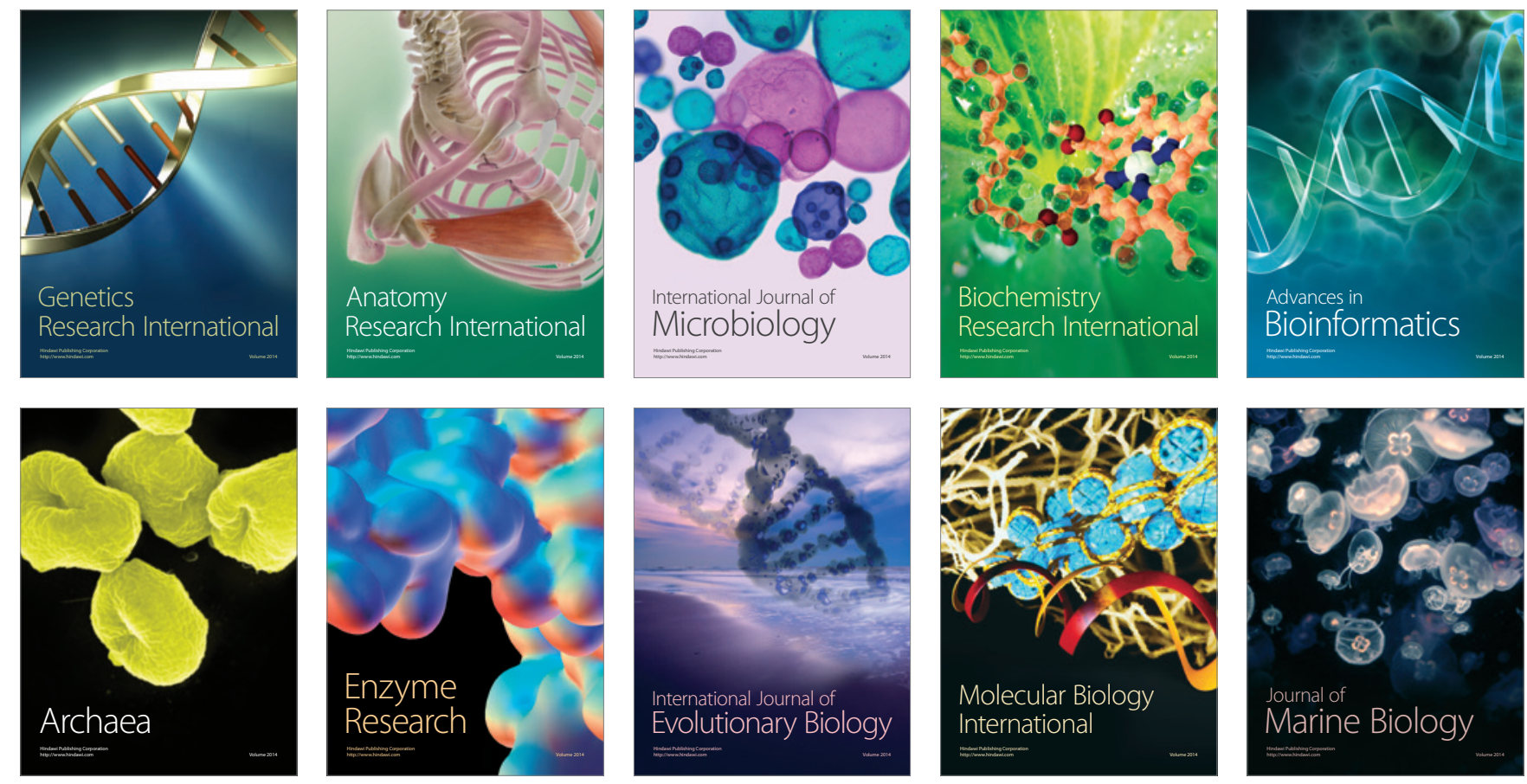